九州大学学術情報リポジトリ

Kyushu University Institutional Repository

囊胞変性を伴う分化型非機能性脺神経内分泌腫瘍に 関する臨床病理学的検討

中島，陽平

http://hdl. hand le. net/2324/2236118

出版情報：Kyushu University，2018，博士（医学），課程博士 バージョン：

権利関係 : 


\title{
Clinicopathological characteristics of non-functioning cystic pancreatic neuroendocrine tumors
}

\author{
Yohei Nakashima ${ }^{a}$, Takao Ohtsuka ${ }^{a}$ *, So Nakamura ${ }^{a}$, Yasuhisa Mori a, Kohei Nakata a, \\ Yoshihiro Miyasaka ${ }^{a}$, Kosei Ishigami ${ }^{b}$, Ryota Matsuda ${ }^{c}$, Yoshinao Oda ${ }^{\text {, }}$ \\ Masafumi Nakamura ${ }^{\text {a, }{ }^{* *}}$
}

a Department of Surgery and Oncology, Graduate School of Medical Sciences, Kyushu University, Fukuoka, Japan

${ }^{\mathrm{b}}$ Department of Clinical Radiology, Graduate School of Medical Sciences, Kyushu University, Fukuoka, Japan

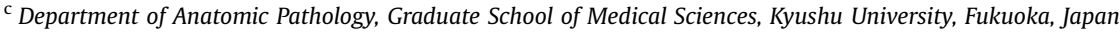

\section{A R T I C L E I N F O}

\section{Article history:}

Received 10 July 2018

Received in revised form

28 October 2018

Accepted 21 November 2018

Available online 22 November 2018

Keywords:

Pancreatic neuroendocrine tumors

Cystic

Somatostatin receptor

\begin{abstract}
A B S T R A C T
Background/objectives: The biological features of cystic pancreatic neuroendocrine tumors (PNETs) remain unclear. The aim of this study was to clarify the clinicopathological characteristics of nonfunctioning PNETs (NF-PNETs) with a cystic component.

Methods: The medical records of 75 patients with NF-PNETs who had undergone resection in our institution were retrospectively reviewed. Clinicopathological factors were compared between PNETs with and without a cystic component. Expression of somatostatin 2 receptor (SSTR-2) was also analyzed. Results: Cystic PNETs were diagnosed in 14 patients (19\%). The proportion of men was significantly higher for cystic than solid PNETs $(79 \%$ vs. $44 \%, P<0.05)$ and cystic PNETs were significantly larger than solid PNETs ( $25 \mathrm{~mm}$ vs. $17 \mathrm{~mm}, P<0.01$ ). However, there were no significant differences in the prevalence of lymph node metastases ( $14 \%$ vs. $10 \%, P=0.64$ ), hepatic metastasis ( $7 \%$ vs. $3 \%, P=0.54$ ), or disease-free survival rate (both $86 \%, P=0.29$ ) between PNETs with and without a cystic component. SSTR-2 expression was more frequently observed in PNETs with a cystic component than in those without (100\% vs. $70 \%, P<0.01$ ).

Conclusions: Although cystic PNETs were larger upon diagnosis than solid PNETs in this study, prognosis after surgical resection did not differ significantly between these types of PNET. Somatostatin receptor scintigraphy and somatostatin analogues may be more useful for diagnosing and treating cystic PNETs, respectively.

() 2018 Published by Elsevier B.V. on behalf of IAP and EPC.
\end{abstract}

\section{Introduction}

Non-functioning pancreatic neuroendocrine tumors (NF-PNETs) are considered rare. However, the incidence has been increasing in Japan [1], likely owing to more widespread knowledge about this disease and advances in radiographic imaging. Although NF-PNETs are generally considered to have lower malignant potential and

\footnotetext{
* Corresponding author. Department of Surgery and Oncology, Graduate School of Medical Sciences, Kyushu University, 3-1-1 Maidashi, Higashi-ku, Fukuoka, 8128582, Japan.

** Corresponding author. Department of Surgery and Oncology, Graduate School of Medical Sciences, Kyushu University, 3-1-1 Maidashi, Higashi-ku, Fukuoka, 8128582, Japan.

E-mail addresses: takao-o@surg1.med.kyushu-u.ac.jp (T. Ohtsuka),mnaka@ surg1.med.kyushu-u.ac.jp (M. Nakamura).
}

better postoperative survival rates than exocrine pancreatic neoplasms, they occasionally have the potential for aggressive invasion and metastases. It is therefore important to predict the malignant potential accurately. Various pathological parameters, including tumor grade, Ki-67 proliferative index, presence of necrosis, presence of perineural invasion, and tumor size have been reported to be associated with the prognosis of patients with PNETs [2-6].

Although most PNETs are solid, some are cystic [7,8]; the latter now being increasingly recognized. The reported incidence of cystic PNETs ranges from $10.8 \%$ to $15.8 \%$ of all PNETs [7-9]. It is generally assumed that cystic changes in PNETs result from tumor necrosis within solid PNETs. Thus, cystic PNETs are thought by some researchers to have similar biological behavior and malignant potential as their solid counterpart [9,10]. However, some conflicting reports have suggested that cystic PNETs have less malignant 
potential than solid PNETs [7,11,12]. Additionally, Cloyd et al. [13] evaluated the percentage of the cystic component of cystic PNETs and showed a close to parallel association between the percentage of the cystic component and a favorable prognosis.

PNET cells are characterized by the expression of several receptors, including somatostatin receptors (SSTRs) types 1 to 5 [14], glucagon-like peptide 1 receptor (GLP-1R) [15], insulin-like growth factor 1 receptor [16], and vascular endothelial growth factor receptor [17]. These receptors regulate intracellular signaling, including the phosphatidyl inositol 3 kinase/AKT/mammalian target of rapamycin (mTOR) pathway, which has a central role in the survival and proliferation of NET cells [18]. Therefore, agents targeting these receptors and the mTOR pathway, such as somatostatin analog (SA), GLP-1, selective insulin-like growth factor 1 receptor tyrosine kinase inhibitor, sunitinib, and everolimus have emerged as useful in the diagnosis and treatment of PNETs.

To our knowledge, no published studies have reported the expression of receptors and activation status of the mTOR signaling cascade in cystic PNETs. Therefore, in this study we aimed to clarify the clinicopathological characteristics and expression of SSTR-2, GLP-1R, and phosphorylated mTOR ( $p$-mTOR) of NF-PNETs with cystic components.

\section{Materials and methods}

\section{Patients and clinicopathological variables}

The Ethics Committee of Kyushu University approved this study (No. 29-186). Medical records of 75 patients with a solitary well differentiated NF-PNET who had undergone resection at our institution between November 1999 to March 2017 were retrospectively reviewed. Clinicopathological factors such as age, sex, presence of multiple endocrine neoplasia type 1 (MEN1) or Von Hippel-Lindau disease (VHL), World Health Organization grade 2017 (G1; Ki-67 index $<2 \%$, G2; Ki-67 index 2-20\%) [19], tumor size, tumor location, presence of lymph node metastases, presence of hepatic metastases, surgical procedure, vascular, perineural, and lymphatic invasion, recurrence, and status of expression of SSTR-2, GLP-1R, and $p$-mTOR as determined by immunohistochemical staining, were compared between NF-PNETs with and without a cystic component.

\section{Definition of cystic components of PNETs}

PNETs were classified as cystic or solid on the basis of preoperative imaging findings. Cystic components were defined as well circumscribed areas without enhancement in contrast-enhanced computed tomography (CT) imaging, as previously reported [20]. Magnetic resonance imaging (MRI) was also performed to confirm that these areas demonstrated high intensity similar to that of water on T2-weighted images (Fig. 1).

\section{Immunohistochemical staining}

Expression of SSTR-2, GLP-1R, and $p$-mTOR was evaluated by immunohistochemical staining. Sections ( $4-\mu \mathrm{m}$ thick) were cut from paraffin-embedded tissues, deparaffinized in xylene, and rehydrated in graded ethanol, as previously described [21]. Endogenous peroxidase activity was blocked by incubation with $3 \%$ hydrogen peroxide in methanol for $30 \mathrm{~min}$. Antigen retrieval was achieved by microwaving the sections in citrate buffer for 20 min. Each section was incubated overnight at $4{ }^{\circ} \mathrm{C}$ with primary antibodies including rabbit monoclonal antibodies against SSTR-2 (ab134152, dilution 1:100; Abcam, Cambridge, UK) and p-mTOR (Ser2448, \#2976, 1:100; Cell Signaling Technology, Danvers, MA, USA) and mouse monoclonal antibodies against GLP-1R (250365, dilution 1:100; ABBIOTEC, San Diego, CA, USA). The sections were sequentially incubated with a biotinylated anti-rabbit or anti-mouse immunoglobulin solution for 20 min. Immunocomplexes were visualized with stable 3, 3'-diaminoenzidine tetrahydrochloride (Sigma Aldrich, St Louis, MO, USA) as a chromogen. Sections were then rinsed with distilled water and counterstained with hematoxylin.

\section{Evaluation of SSTR-2, GLP-1R, and p-mTOR expression levels by} immunohistochemical staining

Immunohistochemical staining of islets of Langerhans was used as an internal positive control for validating SSTR-2 and GLP-1R staining of sections of breast carcinoma as a positive control for p-mTOR.

The following semiquantitative scoring system was used for SSTR-2 expression: 0 for absence of immunoreactivity, 1 for cytoplasmic immunoreactivity only, 2 for membranous reactivity in fewer than $50 \%$ of tumor cells irrespective of the presence of cytoplasmic staining, and 3 for circumferential membranous reactivity in more than $50 \%$ of tumor cells irrespective of the presence of cytoplasmic staining. Immunohistochemical scores 0 and 1 were considered negative, and scores 2 and 3 positive (Fig. 2) [22].

The results of GLP-1R immunoreactivity assessment were expressed as an intensity score (IS) by comparing staining in tumor cells and islets of Langerhans and grading the result as follows: 0 for

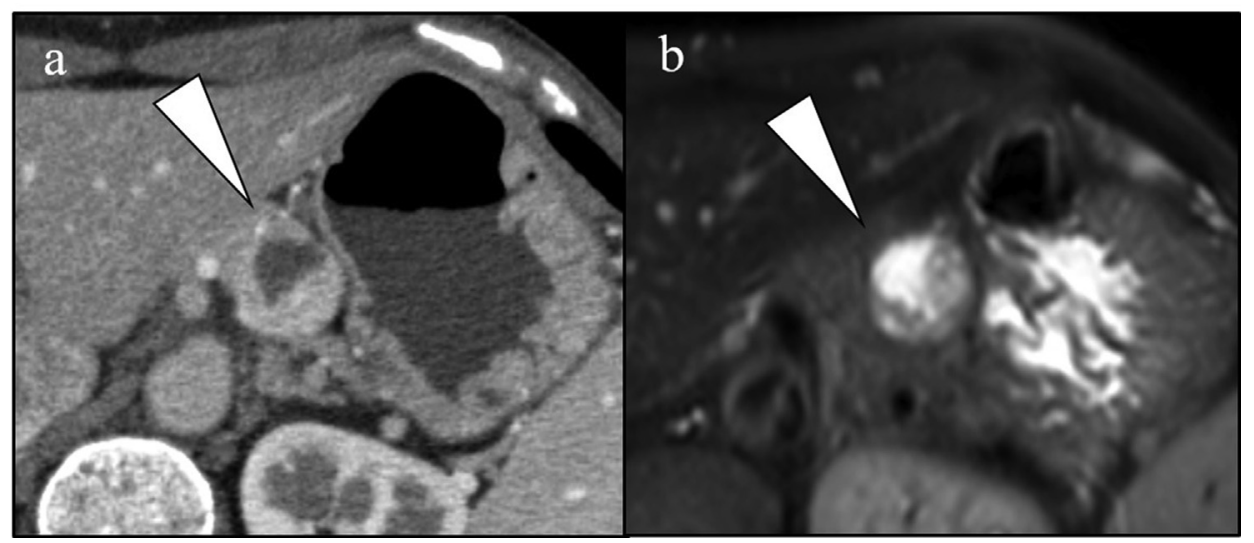

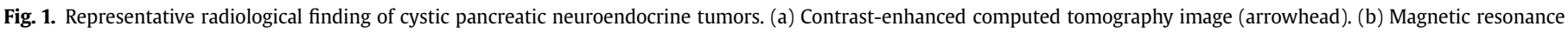
imaging (arrowhead). 


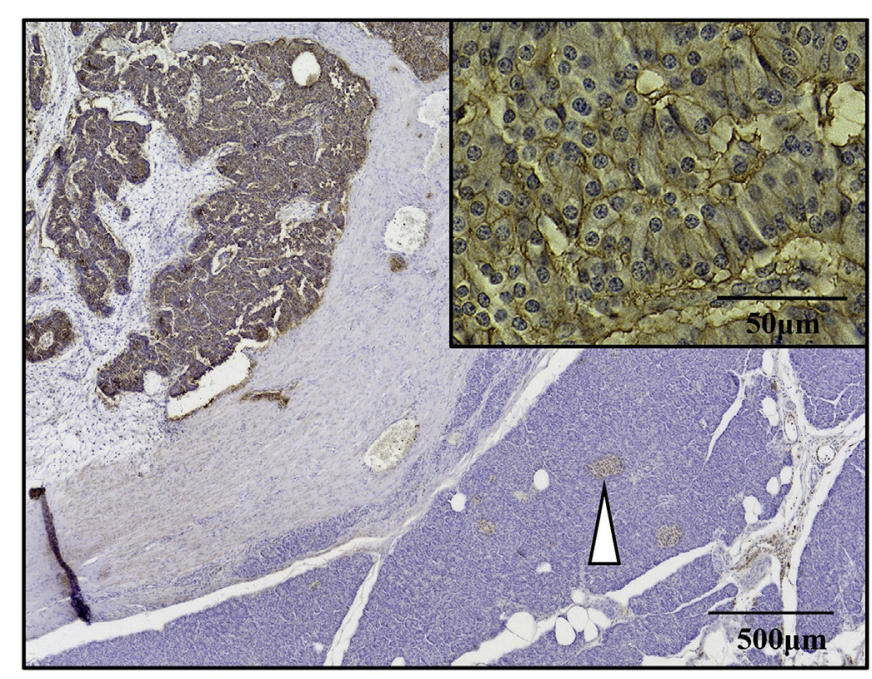

Fig. 2. Representative immunohistochemical findings for somatostatin receptor type 2 (SSTR-2). Positive expression in pancreatic neuroendocrine tumor (original magnification $\times 40$; inset $\times 400$ ). Arrowhead indicates an islet of Langerhans (normally SSTR-2 positive); these were used as positive controls.

no staining (completely negative or extremely faint similar to nonspecific staining of surrounding stromal tissue), 1 for definite staining (positive but weaker than that in islets of Langerhans), 2 for moderate staining (intermediate immunoreactivity), and 3 for strong staining (densely positive as strongly as that in islets of Langerhans). The proportional score (PS) was graded as 0 for staining in less than $10 \%$ of the examined area, 1 for staining in $10 \%$ or greater but less than $30 \%$ of that area, 2 for staining in $30 \%$ or greater but less than $50 \%$ of that area, and 3 for staining in $80 \%$ or greater of that area. The final score (FS) was calculated as IS $\times$ PS, and samples were graded as negative for GLP-1R when FS was 0-3 and positive when FS was 4-12 (Fig. 3) [15,23].

Staining of $p$-mTOR was also scored by using a semi-quantitative immunoreactivity scoring (IRS) system, as previously described $[24,25]$. In brief, Category A scores indicated staining intensity and were 0 (negative), 1 (weak), 2 (moderate), or 3 (strong). Category B scores indicated the percentage of immunoreactive cells and were

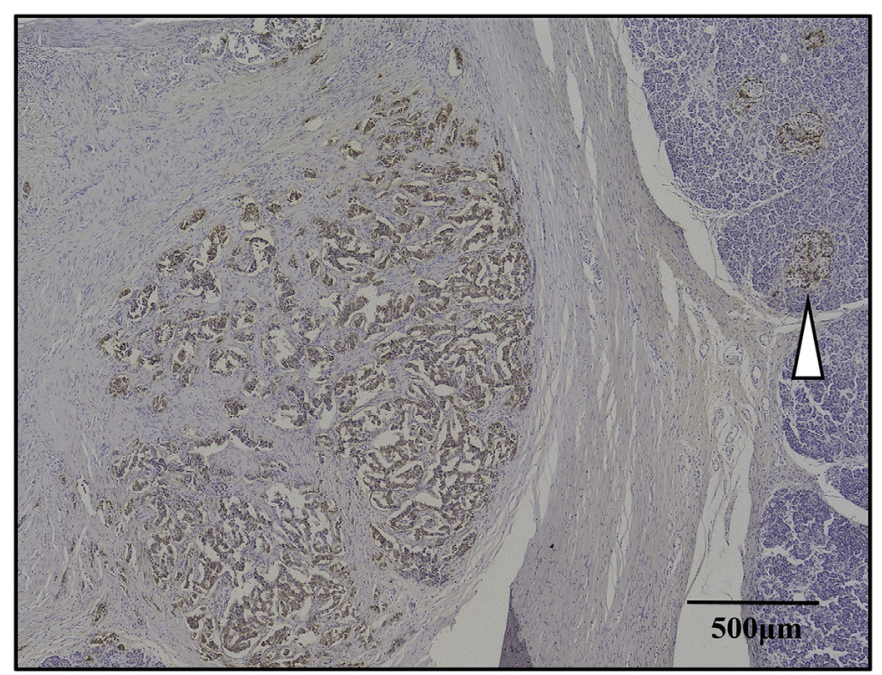

Fig. 3. Representative immunohistochemical findings for glucagon-like peptide 1 receptor (GLP-1R). Positive expression in pancreatic neuroendocrine tumor (original magnification $\times 40$ ). Arrowhead indicates an islet of Langerhans (normally GLP-1R positive); these were used as positive controls.
0 (none), 1 (<10\%), 2 (10\%-50\%), 3 (51\%-80\%), 4 (>80\%). Multiplication of Category A and B scores resulted in an IRS ranging from 0 to 12 for each case. An IRS between 1 and 12 was considered positive and an IRS 0 negative (Fig. 4).

\section{Statistical analysis}

Statistical analysis was performed using JMP13 (SAS Institute, Cary, NC, USA) for Windows software. Fisher's exact probability test or the $\chi^{2}$ test was used to evaluate differences in clinical factors between the two groups. The Mann-Whitney $U$ test was used for continuous data, which were expressed as medians with ranges. Survival curves were constructed by the Kaplan-Meier product-limit method and compared with the log-rank test. Differences were considered statistically significant when the $P$-value was less than 0.05 .

\section{Results}

\section{Clinicopathological features of the study patients and tumors}

There were 38 men and 37 women of median age 57 years (range, $23-80$ years) (Table 1 ). No patient had associated MEN1 or VHL. Thirty patients had PNETs in the pancreatic head and 45 in the pancreatic body to tail. The median tumor size was $17 \mathrm{~mm}$ (range, 3-120 mm). There were 55 patients with pathological NET G1 and 20 with NET G2. Eight patients (11\%) had lymph node metastases and three (4\%) hepatic metastases at the time of surgical resection. Pancreatectomy was performed in 58 patients and enucleation in the remaining 17 in accordance with our therapeutic strategy [26] and curative resection (R0) was achieved in all patients. During a median surveillance period of 50 months (range, 1-232 months), recurrence was identified in nine patients (12\%), including four with lymph node metastases, four with hepatic metastases, and four with local recurrences. Cystic PNETs were diagnosed in 14 patients (19\%). The proportion of men was significantly higher for cystic than for solid PNETs (79\% vs. 44\%, $P<0.05$ ). Cystic PNETs were significantly larger than solid PNETs $(25 \mathrm{~mm}$ vs. $17 \mathrm{~mm}$, $P<0.01)$. On the other hand, there was no significant differences in age $(P=0.70)$ and tumor location $(P=0.10)$ between solid and cystic PNETs. The prevalence of lymph node metastases (14\% vs.

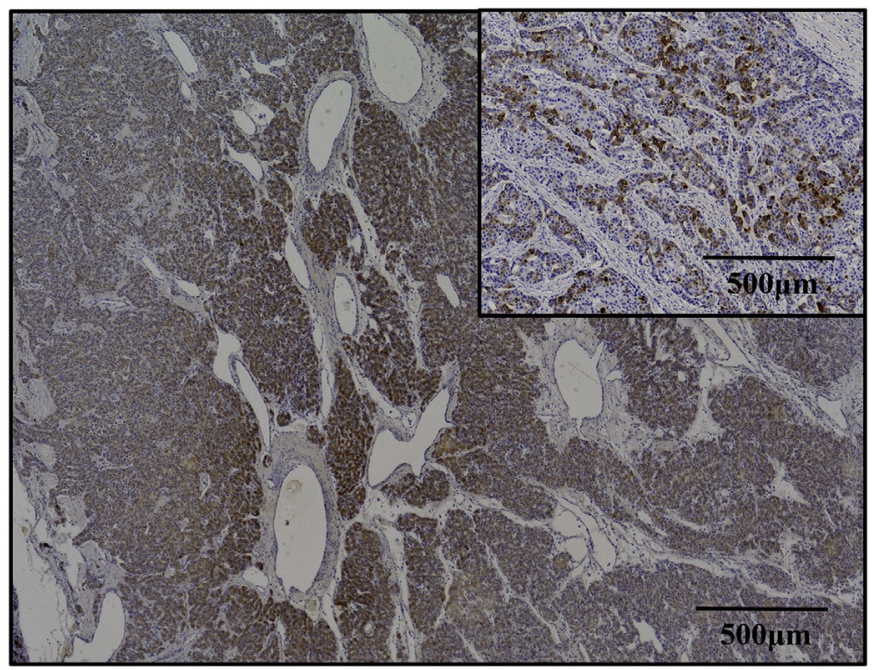

Fig. 4. Representative immunohistochemical findings for phosphorylated mammalian target of rapamycin ( $p$-mTOR). Positive expression in pancreatic neuroendocrine tumo (original magnification $\times 40$ ) and breast carcinoma (inset; original magnification $\times 40$ ), which was as a positive control. 
Table 1

Clinicopathological characteristics according to pancreatic neuroendocrine tumor type.

\begin{tabular}{|c|c|c|c|c|}
\hline & Total $(\mathrm{n}=75)$ & $\begin{array}{l}\text { Cystic PNETs } \\
(\mathrm{n}=14)\end{array}$ & $\begin{array}{l}\text { Solid PNETs } \\
(n=61)\end{array}$ & $P$-value \\
\hline $\begin{array}{l}\text { Age (years), median } \\
\quad \text { (range); }\end{array}$ & $57(23-80)$ & $62(26-80)$ & $57(23-79)$ & 0.70 \\
\hline Sex & & & & $<0.05$ \\
\hline Male & 38 & $11(79 \%)$ & $27(44 \%)$ & \\
\hline Female & 37 & $3(21 \%)$ & $34(56 \%)$ & \\
\hline \multicolumn{5}{|c|}{ Presence of MEN1 ${ }^{\mathrm{a}}$ or $\mathrm{VHL}^{\mathrm{b}}$} \\
\hline Yes & 0 & 0 & 0 & - \\
\hline No & 75 & 14 & 61 & \\
\hline WHO classification & & & & 0.62 \\
\hline G1 & 55 & $11(79 \%)$ & $44(72 \%)$ & \\
\hline G2 & 20 & $3(21 \%)$ & $17(28 \%)$ & \\
\hline $\begin{array}{l}\text { Tumor size (mm), } \\
\text { median (range) }\end{array}$ & $17(3-120)$ & $25(10-57)$ & $16(3-120)$ & $<0.01$ \\
\hline Tumor location & & & & 0.10 \\
\hline Head & 30 & $3(21 \%)$ & $27(44 \%)$ & \\
\hline Body/tail & 45 & $11(79 \%)$ & $34(56 \%)$ & \\
\hline Lymph node metastasis & & & & 0.64 \\
\hline Yes & 8 & $2(14 \%)$ & $6(10 \%)$ & \\
\hline No & 67 & $12(86 \%)$ & $55(90 \%)$ & \\
\hline Hepatic metastasis & & & & 0.54 \\
\hline Yes & 3 & $1(7 \%)$ & $2(3 \%)$ & \\
\hline No & 72 & $13(93 \%)$ & $59(97 \%)$ & \\
\hline Surgical procedure & & & & 0.39 \\
\hline Pancreatectomy & 58 & $12(86 \%)$ & $46(75 \%)$ & \\
\hline Enucleation & 17 & $2(14 \%)$ & $15(25 \%)$ & \\
\hline Vascular invasion & & & & 0.94 \\
\hline Yes & 5 & $1(7 \%)$ & $4(7 \%)$ & \\
\hline Not detected & 70 & $13(93 \%)$ & $57(93 \%)$ & \\
\hline Perineural invasion & & & & 0.75 \\
\hline Yes & 7 & $1(7 \%)$ & $6(10 \%)$ & \\
\hline Not detected & 68 & $13(93 \%)$ & $55(90 \%)$ & \\
\hline Lymphatic invasion & & & & 0.54 \\
\hline Yes & 3 & $1(7 \%)$ & $2(3 \%)$ & \\
\hline Not detected & 72 & $13(93 \%)$ & $59(97 \%)$ & \\
\hline Recurrence, yes ${ }^{c}$ & $9(12 \%)$ & $1(7 \%)$ & $8(13 \%)$ & 0.76 \\
\hline Liver & 4 & 0 & 4 & \\
\hline Lymph node & 4 & 0 & 4 & \\
\hline Local & 4 & 1 & 3 & \\
\hline $\begin{array}{l}\text { Five-year disease-free } \\
\text { survival rate (\%) }\end{array}$ & $86 \%$ & $86 \%$ & $86 \%$ & 0.29 \\
\hline
\end{tabular}

PNETs, pancreatic neuroendocrine tumors; WHO, World Health Organization.

a Multiple endocrine neoplasia type 1 .

b Von Hippel-Lindau disease.

c Three patients had recurrences in multiple sites.

$10 \%, P=0.64$ ), hepatic metastasis (7\% vs. $3 \%, P=0.54$ ), and histopathological evidence of invasion did not differ significantly between the two groups. Moreover, the disease-free survival rate did not differ significantly between PNETs with and without a cystic component $(P=0.29)$ (Fig. 5).

Table 2 shows a comparison of the clinicopathological characteristics between NET G1 and G2. NET G2 had significantly larger tumor size ( $24 \mathrm{~mm}$ vs. $15 \mathrm{~mm}, P<0.01$ ), higher prevalence of lymph node $(30 \%$ vs. $2 \%, \mathrm{P}<0.01)$ and hepatic $(15 \%$ vs. $0 \%, P<0.01)$ metastases, higher incidence of vascular $(20 \%$ vs. $2 \%, \mathrm{P}<0.01)$ and perineural $(25 \%$ vs. $4 \%, P<0.01)$ invasion, higher recurrence rate (35\% vs. $45 \%, P<0.01$ ), and lower 5 -year disease-free survival rate (64\% vs. $95 \%, P<0.01$ ). On the other hand, other factors including incidence of cystic PNETs were not significantly different between NET G1 and G2.

\section{Immunohistochemical analysis of primary tumor}

Paraffin-embedded tissues were not available for five of the 75 patients; thus, only samples from the remaining 70 patients were evaluated. The results are presented in Table 3. Positive SSTR-2

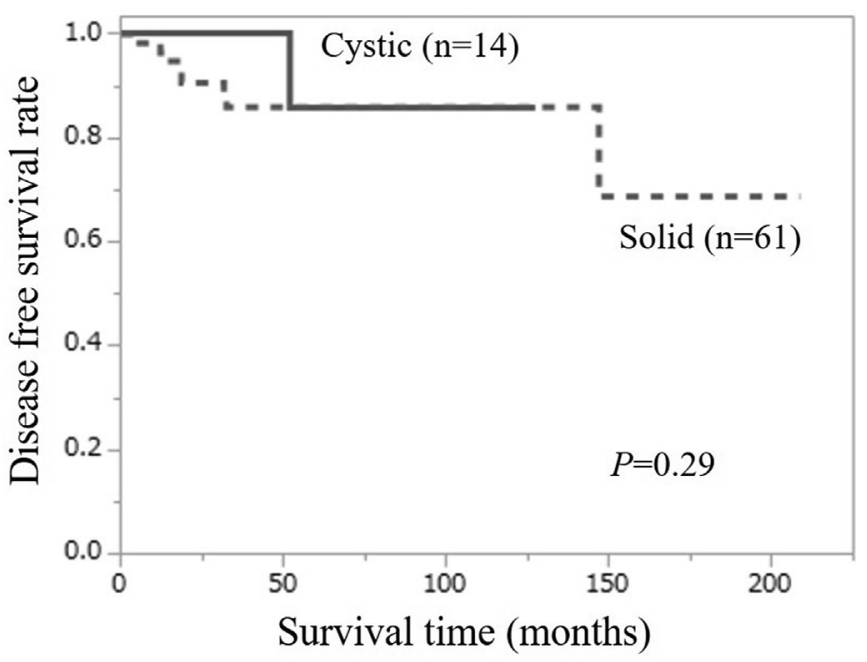

Fig. 5. Disease-free survival curves after resection of pancreatic neuroendocrine tumors with or without a cystic component. The difference between the cystic and solid tumors is not statistically significant.

expression was significantly associated with the presence of cystic change. However, the correlation between GLP-1R/p-mTOR expression and the presence of cystic change was not significant.

Table 2

Clinicopathological characteristics according to WHO grading of pancreatic neuroendocrine tumors.

\begin{tabular}{|c|c|c|c|c|}
\hline & Total $(\mathrm{n}=75)$ & $\mathrm{G} 1(\mathrm{n}=55)$ & $\mathrm{G} 2(\mathrm{n}=20)$ & $P$-value \\
\hline $\begin{array}{l}\text { Age (years), median } \\
\text { (range); }\end{array}$ & $57(23-80)$ & $57(23-80)$ & $56(34-73)$ & 0.40 \\
\hline Sex & & & & 0.55 \\
\hline Male & 38 & $29(53 \%)$ & $9(45 \%)$ & \\
\hline Female & 37 & $26(47 \%)$ & $11(55 \%)$ & \\
\hline \multicolumn{5}{|c|}{ Presence of MEN $1^{\mathrm{a}}$ or $\mathrm{VHL}^{\mathrm{b}}$} \\
\hline Yes & 0 & 0 & 0 & - \\
\hline No & 75 & 55 & 20 & \\
\hline Cystic change & & & & 0.25 \\
\hline Yes & 20 & $11(20 \%)$ & $3(15 \%)$ & \\
\hline No & 55 & $44(80 \%)$ & $17(85 \%)$ & \\
\hline $\begin{array}{l}\text { Tumor size (mm), } \\
\text { median (range) }\end{array}$ & $17(3-120)$ & $15(3-45)$ & $24(7-120)$ & $<0.01$ \\
\hline Tumor location & & & & 0.29 \\
\hline Head & 30 & $20(36 \%)$ & $10(50 \%)$ & \\
\hline Body/tail & 45 & $35(64 \%)$ & $10(50 \%)$ & \\
\hline Lymph node metastasis & & & & $<0.01$ \\
\hline Yes & 8 & $2(4 \%)$ & $6(30 \%)$ & \\
\hline No & 67 & $53(96 \%)$ & $14(70 \%)$ & \\
\hline Hepatic metastasis & & & & $<0.01$ \\
\hline Yes & 3 & $0(0 \%)$ & $3(15 \%)$ & \\
\hline No & 72 & $55(100 \%)$ & $17(85 \%)$ & \\
\hline Vascular invasion & & & & $<0.01$ \\
\hline Yes & 5 & $1(2 \%)$ & $4(20 \%)$ & \\
\hline Not detected & 70 & $54(98 \%)$ & $16(80 \%)$ & \\
\hline Perineural invasion & & & & $<0.01$ \\
\hline Yes & 7 & $2(4 \%)$ & $5(25 \%)$ & \\
\hline Not detected & 68 & $53(96 \%)$ & $15(75 \%)$ & \\
\hline Lymphatic invasion & & & & 0.14 \\
\hline Yes & 3 & $1(2 \%)$ & $2(10 \%)$ & \\
\hline Not detected & 72 & $54(985)$ & $18(90 \%)$ & \\
\hline Recurrence, yes ${ }^{c}$ & $9(14 \%)$ & $2(4 \%)$ & $7(35 \%)$ & $<0.01$ \\
\hline Liver & 4 & 0 & 4 & \\
\hline Lymph node & 4 & 0 & 4 & \\
\hline Local & 4 & 2 & 2 & \\
\hline $\begin{array}{l}\text { Five-year disease-free } \\
\text { survival rate (\%) }\end{array}$ & 86 & 95 & 64 & $<0.01$ \\
\hline
\end{tabular}

WHO, World Health Organization.

a Multiple endocrine neoplasia type 1 .

b Von Hippel-Lindau disease.

c Three patients had recurrences at multiple sites. 
Table 3

Analysis of somatostatin receptor type 2 (SSTR-2), glucagon-like peptide 1 receptor (GLP-1R), and phosphorylated mammalian target of rapamycin ( $p$-mTOR) expression in primary pancreatic neuroendocrine tumors with or without a cystic component.

\begin{tabular}{lllll}
\hline & $\begin{array}{l}\text { Total } \\
(\mathrm{n}=70)\end{array}$ & $\begin{array}{l}\text { Cystic PNETs } \\
(\mathrm{n}=14)\end{array}$ & $\begin{array}{l}\text { Solid PNETs } \\
(\mathrm{n}=56)\end{array}$ & P-value \\
\hline $\begin{array}{l}\text { Expression of SSTR-2 } \\
\quad \text { Positive }\end{array}$ & $53(76 \%)$ & $14(100 \%)$ & $39(70 \%)$ & $<0.01$ \\
$\quad 17(24 \%)$ & $0(0 \%)$ & $17(30 \%)$ & 0.81 \\
$\quad \begin{array}{l}\text { Negative } \\
\text { Expression of GLP-1R }\end{array}$ & $33(47 \%)$ & $7(50 \%)$ & $26(46 \%)$ & \\
$\quad \begin{array}{l}\text { Positive } \\
\quad \text { Negative }\end{array}$ & $37(53 \%)$ & $7(50 \%)$ & $30(54 \%)$ & 0.90 \\
$\quad \begin{array}{llll}\text { Expression of } p \text {-mTOR } \\
\quad \text { Positive }\end{array}$ & $31(44 \%)$ & $6(43 \%)$ & $25(45 \%)$ & \\
$\quad$ Negative & $39(56 \%)$ & $8(57 \%)$ & $31(55 \%)$ & \\
\hline
\end{tabular}

Additionally, there was no difference in disease-free survival rate between the positive and negative expression groups for the three receptors assessed.

\section{Cystic change and immunohistochemical analysis of metastases}

As presented in Table 1, eight patients had lymph node metastases, three of whom also had hepatic metastases. Samples were available for only nine of these 11 metastatic sites (details in Table 4); thus, expression of SSTR-2, GLP-1R, and p-mTOR was assessed by immunohistochemical analyses in only those nine samples. The pattern of expression of SSTR-2 was consistent between primary and metastatic sites in all nine examined pairs of samples, whereas patterns of expression of GLP-1R/p-mTOR were not always consistent between primary and metastatic sites. One of two patients with primary cystic PNETs also had cystic changes in hepatic metastases, and the expression pattern of SSTR-2/GLP-1R was similar, whereas that of $p$-mTOR differed between the primary and metastatic sites.

\section{Discussion}

In the present study, we found the following: (1) cystic PNETs were larger than solid PNETs at diagnosis; (2) the proportion of men was significantly higher for cystic than solid PNETs; (3) postoperative prognosis did not differ significantly between PNETs with and without a cystic component; and (4) positive SSTR-2 expression was significantly associated with the presence of cystic change.

Cystic PNETs are not excessively rare, reportedly accounting for up to $11.5 \%$ of all resected PNETs $[8,9,11,27]$. There are two main hypotheses regarding the presence of cystic components in PNETs. Some investigators speculate that the fibrous capsules of PNETs hinder blood supply to the lesion, leading to necrosis and subsequent cystic degeneration [9], whereas others postulate that hemorrhage may occur in PNETs, which are highly vascular, and that cystic degeneration is a consequence of such hemorrhage [28]. However, the precise mechanisms have not been fully elucidated.

Cystic PNETs have been reported to be larger and less likely to be benign than their solid counterparts [9]. In some recent studies, it has been noted that cystic PNETs may have a more favorable prognosis than solid PNETs. In these studies, cystic PNETs had lower Ki-67 proliferation indices [7], and less perineural invasion [7], vascular invasion [7], lymph node metastases [7,11,13], and synchronous distant metastases [7], than solid PNETs [7,11,13]. In another study it was found that the presence of a cystic component is a negative predictor of malignant change [8]. In the present study, cystic PNETs were larger than solid PNETs; however, their prognosis did not differ significantly from that of solid PNETs. Although tumor size is currently considered the major determinant of the malignant potential of PNETs, malignant potential may also be associated with presence of cystic change. Cloyd et al. reported that the proportion of cystic components within PNETs approximately parallels the prognosis [13]. When predicting the malignant potential of cystic PNETs, both tumor size and proportion of cystic components should be considered.

Cystic PNETs are reportedly more likely to be present in a patient with MEN1 than solid PNETS [29]. MEN1-associated PNETs are almost always multifocal and usually distributed throughout the pancreatic parenchyma; most of these tumors are small microadenomas. In the present study, to avoid the effect of other tumors in the same pancreas on prognosis, we included only patients with solitary PNETs; consequently, there were no patients with MEN1 in the study cohort. Thus, we were unable to determine the relationship between MEN1 and cystic PNETs; however, a diagnosis of MEN1 should be considered preoperatively when assessing patients with cystic PNETs.

In the present study, a significantly higher proportion of men had cystic than solid PNETs. A previous meta-analysis of the clinicopathological characteristics of cystic PNETs reported the same tendency; however, it was not significant in that study [1]. Cloyd et al. reported that the proportion of men with cystic PNETs increases in parallel with the percentage of cystic components and that men account for $87.5 \%$ of purely cystic PNETs [13]. Male sex hormones may affect the formation of cystic components in PNETs.

Somatostatin, an endogenous peptide hormone, inhibits cellular proliferation and secretion of hormones. Several studies have reported that positive SSTR-2 expression in PNETs is associated with better survival [30,31]. However, in the present study, the diseasefree survival rates of patients with cystic and solid PNETs did not differ significantly despite a significant difference in SSTR-2 expression between these two entities. Possible explanations for this discrepancy include the fact that about 70\% of solid PNETs also expressed SSTR-2, the sample size was small, and few patients had metastases. It may be true that disease-free survival rate does not

Table 4

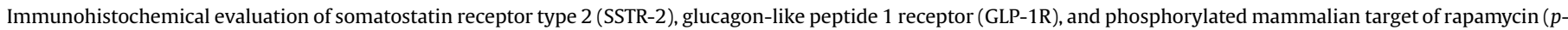
mTOR) in metastases.

\begin{tabular}{|c|c|c|c|c|c|c|c|c|c|c|c|c|}
\hline Patient & Primary & & & & Lymph node metastasis & & & & Hepatic metastasis & & & \\
\hline & Cystic change & SSTR-2 & GLP-1R & $p$-mTOR & Cystic change & SSTR-2 & GLP-1R & $p$-mTOR & Cystic change & SSTR-2 & GLP-1R & $p$-mTOR \\
\hline 1 & - & NA & NA & NA & - & NA & NA & NA & No hepatic metastasis & & & \\
\hline 2 & - & + & - & - & - & NA & NA & NA & No hepatic metastasis & & & \\
\hline 3 & - & + & + & + & - & + & + & - & No hepatic metastasis & & & \\
\hline 4 & - & + & + & - & - & + & + & - & No hepatic metastasis & & & \\
\hline 5 & + & + & - & - & - & + & - & - & + & + & - & + \\
\hline 6 & - & - & + & + & - & - & - & - & - & - & - & - \\
\hline 7 & - & + & + & - & - & + & - & - & - & + & - & + \\
\hline 8 & + & + & - & + & - & + & - & - & No hepatic metastasis & & & \\
\hline
\end{tabular}

NA, not available. 
differ between solid and cystic PNETs. As to the biological significance of SSTR-2 positivity on cystic change in PNETs, this remains unclear.

SSTR scintigraphy may be more useful for diagnosing cystic PNETs because of their high prevalence of positive SSTR-2 expression. Singhi et al. reported that $43 \%$ of cystic PNETs are misdiagnosed as intraductal papillary mucinous neoplasm, mucinous cystic neoplasm, adenocarcinoma, or solid-pseudopapillary neoplasm by imaging [7]. Endoscopic ultrasound (EUS)-guided fine needle aspiration (FNA) cytology and immunohistochemical staining for neuroendocrine markers can achieve diagnosis of the majority of cystic PNETs, the reported sensitivity being 78\% [32]. However, EUSFNA carries risks of peritoneal dissemination and seeding of tumor cells along the needle tract [33]. SSTR scintigraphy may be more useful for discriminating cystic PNETs without such risks.

SSTR is also a target of PNET treatment. SA has dual effects on PNETs including antitumor and hormone-reducing effects [34]. In addition, SSTR has been used for peptide receptor-targeted radiotherapy [34]. Therefore, SSTR targeted therapy may also be more useful in cystic PNETs.

Although we were unable to determine the significance of expression of GLP-1R and $p$-mTOR in cystic PNETs, we found that the pattern of expression of GLP-1R/p-mTOR often differed between primary and metastatic PNETs, including those with cystic component. This finding indicates that PNETs can be heterogeneous and that GLP-1R/p-mTOR, which are major molecular targets for the diagnosis or treatment of PNETs, are not involved in the major mechanism of cystic change in PNETs. Further investigation is necessary to clarify the molecular-based mechanism(s) for the cystic change in PNETs.

This study had several limitations. First, it was a retrospective trial of a small group of patients who were treated at a single hospital. Second, only resected PNETs were included, indicating the possible presence of selection biases, and we were unable to ascertain the prognosis of patients with small cystic PNETs who were managed conservatively. Third, we did not analyze SSTR expression by SSTR scintigraphy because this technique was not covered by the Japanese National Health Insurance system when the study patients' tumors were resected.

In conclusion, although cystic PNETs are larger than solid PNETs, their prognoses after surgical resection are similar. SSTR scintigraphy and SA may be more useful for the diagnosis and treatment of cystic PNETs, respectively.

\section{Acknowledgements}

This study was supported by a Grant-in-Aid from the Japan Society for the Promotion of Sciences for Scientific Research (B) (Grant Number 16H05417). We thank Dr Trish Reynolds, MBBS, FRACP, and H. Nikki March, PhD, from Edanz Group (www. edanzediting.com/ac) for editing a draft of this manuscript. The authors declare no conflicts of interest.

\section{References}

[1] Ito T, Igarashi $\mathrm{H}$, Nakamura K, Sasano H, Okusaka T, Takano K, et al. Epidemiological trends of pancreatic and gastrointestinal neuroendocrine tumors in Japan: a nationwide survey analysis. J Gastroenterol 2015;50:58-64.

[2] Demir R, Pohl J, Agaimy A, Peros G, Perrakis A, Merkel S, et al. Necrosis and angioinvasion predict adverse outcome in pancreatic neuroendocrine tumors after curative surgical resection: results of a single-center series. World J Surg 2011;35:2764-72.

[3] Tomassetti P, Campana D, Piscitelli L, Casadei R, Santini D, Nori F, et al Endocrine pancreatic tumors: factors correlated with survival. Ann Oncol 2005:16:1806-10.

[4] Fischer L, Kleeff J, Esposito I, Hinz U, Zimmermann A, Friess H, et al. Clinical outcome and long-term survival in 118 consecutive patients with neuroendocrine tumours of the pancreas. Br J Surg 2008;95:627-35.
[5] Tsutsumi K, Ohtsuka T, Fujino M, Nakashima H, Aishima S, Ueda J, et al. Analysis of risk factors for recurrence after curative resection of welldifferentiated pancreatic neuroendocrine tumors based on the new grading classification. J Hepatobiliary Pancreat Sci 2014;21:418-25.

[6] Yamamoto Y, Okamura Y, Uemura S, Sugiura T, Ito T, Ashida R, et al. Vascularity and tumor size are significant predictors for recurrence after resection of a pancreatic neuroendocrine tumor. Ann Surg Oncol 2017;24:2363-70.

[7] Singhi AD, Chu LC, Tatsas AD, Shi C, Ellison TA, Fishman EK, et al. Cystic pancreatic neuroendocrine tumors: a clinicopathologic study. Am J Surg Pathol 2012;36:1666-73.

[8] Boninsegna L, Partelli S, D'Innocenzio MM, Capelli P, Scarpa A, Bassi C, et al. Pancreatic cystic endocrine tumors: a different morphological entity associated with a less aggressive behavior. Neuroendocrinology 2010;92:246-51.

[9] Goh BK, Ooi LL, Tan YM, Cheow PC, Chung YF, Chow PK, et al. Clinico-pathological features of cystic pancreatic endocrine neoplasms and a comparison with their solid counterparts. Eur J Surg Oncol 2006;32:553-6.

[10] Gaujoux S, Tang L, Klimstra D, Gonen M, Brennan MF, D'Angelica M, et al. The outcome of resected cystic pancreatic endocrine neoplasms: a case-matched analysis. Surgery 2012;151:518-25.

[11] Koh YX, Chok AY, Zheng HL, Tan CS, Goh BK. A systematic review and metaanalysis of the clinicopathologic characteristics of cystic versus solid pancreatic neuroendocrine neoplasms. Surgery 2014;156:83-96. e82.

[12] Yano M, Misra S, Salter A, Carpenter DH. Assessment of disease aggression in cystic pancreatic neuroendocrine tumors: a CT and pathology correlation study. Pancreatology 2017;17:605-10.

[13] Cloyd JM, Kopecky KE, Norton JA, Kunz PL, Fisher GA, Visser BC, et al. Neuroendocrine tumors of the pancreas: degree of cystic component predicts prognosis. Surgery 2016;160:708-13.

[14] Nakayama Y, Wada R, Yajima N, Hakamada K, Yagihashi S. Profiling of somatostatin receptor subtype expression by quantitative PCR and correlation with clinicopathological features in pancreatic endocrine tumors. Pancreas 2010;39:1147-54.

[15] Cases AI, Ohtsuka T, Fujino M, Ideno N, Kozono S, Zhao M, et al. Expression of glucagon-like peptide 1 receptor and its effects on biologic behavior in pancreatic neuroendocrine tumors. Pancreas 2014;43:1-6.

[16] Furukawa M, Raffeld M, Mateo C, Sakamoto A, Moody TW, Ito T, et al. Increased expression of insulin-like growth factor i and/or its receptor in gastrinomas is associated with low curability, increased growth, and development of metastases. Clin Canc Res 2005;11:3233-42.

[17] Couvelard A, O'Toole D, Turley H, Leek R, Sauvanet A, Degott C, et al. Microvascular density and hypoxia-inducible factor pathway in pancreatic endocrine tumours: negative correlation of microvascular density and vegf expression with tumour progression. Br J Canc 2005;92:94-101.

[18] Barbieri F, Albertelli M, Grillo F, Mohamed A, Saveanu A, Barlier A, et al. Neuroendocrine tumors: insights into innovative therapeutic options and rational development of targeted therapies. Drug Discov Today 2014;19:458-68.

[19] Lloyd RV, et al., editors. WHO classification of tumours of endocrine organs. fourth ed. Lyon France: IARC Press; 2017.

[20] Kawamoto S, Johnson PT, Shi C, Singhi AD, Hruban RH, Wolfgang CL, et al. Pancreatic neuroendocrine tumor with cystlike changes: evaluation with MDCT. AJR Am J Roentgenol 2013;200:W283-90.

[21] Ikenaga N, Ohuchida K, Mizumoto K, Yu J, Kayashima T, Hayashi A, et al. Characterization of CD24 expression in intraductal papillary mucinous neoplasms and ductal carcinoma of the pancreas. Hum Pathol 2010;41:1466-74.

[22] Volante M, Brizzi MP, Faggiano A, La Rosa S, Rapa I, Ferrero A, et al. Somatostatin receptor type $2 \mathrm{a}$ immunohistochemistry in neuroendocrine tumors: a proposal of scoring system correlated with somatostatin receptor scintigraphy. Mod Pathol 2007;20:1172-82.

[23] Furukawa T, Kuboki Y, Tanji E, Yoshida S, Hatori T, Yamamoto M, et al. Wholeexome sequencing uncovers frequent GNAS mutations in intraductal papillary mucinous neoplasms of the pancreas. Sci Rep 2011;1:161.

[24] Kasajima A, Pavel M, Darb-Esfahani S, Noske A, Stenzinger A, Sasano H, et al. mTOR expression and activity patterns in gastroenteropancreatic neuroendocrine tumours. Endocr Relat Canc 2011;18:181-92.

[25] Komori Y, Yada K, Ohta M, Uchida H, Iwashita Y, Fukuzawa K, et al, Mammalian target of rapamycin signaling activation patterns in pancreatic neuroendocrine tumors. J Hepatobiliary Pancreat Sci 2014;21:288-95.

[26] Tsutsumi K, Ohtsuka T, Mori Y, Fujino M, Yasui T, Aishima S, et al. Analysis of lymph node metastasis in pancreatic neuroendocrine tumors (PNETs) based on the tumor size and hormonal production. J Gastroenterol 2012;47:678-85.

[27] Figueiredo FA, Giovannini M, Monges G, Charfi S, Bories E, Pesenti C, et al. Pancreatic endocrine tumors: a large single-center experience. Pancreas 2009;38:936-40.

[28] Takeshita K, Furui S, Makita K, Yamauchi T, Irie T, Tsuchiya K, et al. Cystic islet cell tumors: radiologic findings in three cases. Abdom Imag 1994;19:225-8.

[29] Bordeianou L, Vagefi PA, Sahani D, Deshpande V, Rakhlin E, Warshaw AL, et al. Cystic pancreatic endocrine neoplasms: a distinct tumor type? J Am Coll Surg 2008;206:1154-8.

[30] Okuwaki K, Kida M, Mikami T, Yamauchi H, Imaizumi H, Miyazawa S, et al, Clinicopathologic characteristics of pancreatic neuroendocrine tumors and relation of somatostatin receptor type 2a to outcomes. Cancer 2013;119: 4094-102.

[31] Mehta S, de Reuver PR, Gill P, Andrici J, D'Urso L, Mittal A, et al. Somatostatin receptor SSTR-2a expression is a stronger predictor for survival than Ki-67 in pancreatic neuroendocrine tumors. Medicine (Baltim) 2015;94. e1281. 
[32] Chen L, Nassar A, Kommineni VT, Zarka MA, Zhang J, Faigel D, et al. Endoscopic ultrasonography-guided fine-needle aspiration cytology of surgically confirmed cystic pancreatic neuroendocrine tumors: a Mayo Clinic experience. J Am Soc Cytopathol 2015;4:335-43.

[33] Minaga K, Takenaka M, Katanuma A, Kitano M, Yamashita Y, Kamata K, et al. Needle tract seeding: an overlooked rare complication of endoscopic ultrasound-guided fine-needle aspiration. Oncology 2017;93(Suppl 1): $107-12$.

[34] Falconi M, Eriksson B, Kaltsas G, Bartsch DK, Capdevila J, Caplin M, et al. ENETS consensus guidelines update for the management of patients with functional pancreatic neuroendocrine tumors and non-functional pancreatic neuroendocrine tumors. Neuroendocrinology 2016;103:153-71. 